\title{
Childhood body mass index in relation to future risk of oesophageal adenocarcinoma
}

\author{
M B Cook , N D Freedman ${ }^{1}$, M Gamborg ${ }^{2}$, T I A Sørensen ${ }^{2,3}$ and J L Baker ${ }^{\star 2,3}$ \\ ${ }^{1}$ Division of Cancer Epidemiology and Genetics, National Cancer Institute, NIH, DHHS, Bethesda, MD, USA; ${ }^{2}$ Institute of \\ Preventive Medicine, Bispebjerg and Frederiksberg Hospital, The Capital Region, Copenhagen, Denmark and ${ }^{3}$ The Novo Nordisk \\ Foundation Center for Basic Metabolic Research, Faculty of Health and Medical Sciences, University of Copenhagen, \\ Copenhagen, Denmark
}

Background: Middle-aged obese adults are at substantially elevated risk of oesophageal adenocarcinoma. It is unclear whether this risk originates earlier in life.

Methods: We assessed associations between childhood body mass index (BMI) and height-measured annually between ages 7 and 13 - with adult oesophageal adenocarcinoma in a cohort from the Copenhagen School Health Records Register. Analyses included 255053 children born during 1930-1971. Danish Cancer Registry linkage provided outcomes. We calculated hazard ratios (HRs) and 95\% confidence intervals (Cls) using Cox proportional hazards regression.

Results: During 5.4 million person-years of follow-up, 254 (216 males) incident oesophageal adenocarcinomas occurred. At each examined age, cancer risk increased linearly per unit BMI z-score, although associations were only statistically significant for ages 9-13. The HR for the age of 13 years was 1.31 (95\% Cl: 1.13, 1.51) per unit BMI z-score. Associations were similar in men and women and across birth cohorts. Childhood height was not related to cancer risk in men but was in women, although these analyses included just 38 female cases. HRs per unit height $z$-score at the age of 13 years were $1.04(0.90,1.19)$ in males and $1.77(1.27,2.47)$ in females, with similar results observed at the other examined ages.

Conclusion: Individuals with higher childhood BMI were at elevated risk of oesophageal adenocarcinoma, even though these cancers occurred many decades later in life. Although the mechanisms require further investigation, our findings provide additional evidence for the long-term health risks of childhood obesity.

Childhood obesity has dramatically increased over the last four decades especially in high income countries within Europe and North America (Bua et al, 2007; Claire Wang et al, 2011). Excess weight during childhood has been both associated with disease during childhood-such as type 2 diabetes mellitus, metabolic syndrome, hyperandrogenism, sleep disturbance, liver and other gastrointestinal diseases (Adegboye et al, 2010; Abrams and Levitt Katz, 2011) - as well as with disease in adults, including type II diabetes mellitus, coronary artery disease, dyslipidaemia, hypertension, non-alcoholic fatty liver disease, infertility, asthma and premature death (Baker et al, 2007; Kelsey et al, 2014a).

Concurrent with the 'obesity epidemic', the incidence of oesophageal adenocarcinoma has increased over 600\% in the
United States, with similar increases observed in other high income European countries (Cook et al, 2009; Kroep et al, 2014). Reasons for this increase in incidence are poorly defined; however, obesity is a major risk factor for this malignancy (Kong et al, 2011; Lofdahl et al, 2011; Hoyo et al, 2012; Kubo et al, 2013). Studies of adult anthropometry-typically captured within the period of 10 years before diagnosis in middle age-have shown strong positive associations between body mass index (BMI)/visceral adiposity and oesophageal adenocarcinogenesis (Hoyo et al, 2012; Kubo et al, 2013), with gastroesophageal reflux (Pandolfino et al, 2006; Derakhshan et al, 2011) and dysfunctional metabolic effects (Reid et al, 2010; Ryan et al, 2011) being primary candidates for underlying causal mechanisms. Childhood obesity may directly 
affect the risk of oesophageal adenocarcinoma. Indeed, BMI is positively associated with gastroesophageal reflux disease in children (Malaty et al, 2009; Pashankar et al, 2009; Koebnick et al, 2011), which can lead to complications such as esophagitis (Tolaymat and Chapman, 1998; Ruigomez et al, 2010; Nguyen et al, 2011) and Barrett's metaplasia (Cooper et al, 1987; Tolaymat and Chapman, 1998; Nguyen et al, 2011). However, specific data evaluating the hypothesis that childhood obesity is related to oesophageal adenocarcinoma risk are scarce.

Therefore, we conducted a prospective analysis of measured childhood anthropometry and subsequent risk of oesophageal adenocarcinoma in the Copenhagen School Health Records Register (CSHRR), obtaining cancer diagnoses from the Danish Cancer Registry.

\section{METHODS}

Cohort for analysis. The CSHRR has been described in detail previously (Baker et al, 2009). In brief, the CSHRR includes 372636 school children who ever attended school in the municipality of Copenhagen, Denmark. School-based health care included annual assessments of each child, components of which have subsequently been computerized for individuals born in 1930-1989. More recent years continue to be added. Throughout this time period, childhood weight and height were measured by a school physician or nurse, with the child wearing minimal clothing and no shoes.

Over the long period covered by the CSHRR, ages of compulsory education have varied for both starting (5-7 years) and ending (13-16 years) one's formal education; thus, analyses of childhood BMI and height were restricted to ages 7 through 13 years, as these were the predominant ages with available information. For our analyses of oesophageal adenocarcinoma, we restricted the data set to birth cohorts 1930-1971 and cancer diagnosis to those occurring at the age of 40 or later, as there were only three recorded cases of this malignancy in younger ages and zero cases among participants born after 1971. We excluded seven subjects who had outlying BMI or height $z$-scores $(<-4.5$ or $>4.5$ ) at all ages.

Data linkage. In 1968, the Danish Central Office of Civil Registration assigned a personal identification number (ID number) to every citizen. Children attending school in 1968, and thereafter, had the ID number recorded on their health card. For health cards completed before 1968, names, sex and date of birth were used to match health cards with ID numbers. ID numbers were successfully identified for 329968 (89\%) of the 372636 children in the CSHRR. Individuals who died or emigrated before 1968 were never assigned an ID number.

The ID number enables linkage to the Danish Cancer Registry and the Central Person Register (vital statistics) which, for these analyses, were used to provide outcome information on oesophageal adenocarcinoma until the last date of follow-up of 31 December 2011. Oesophageal adenocarcinoma was defined using codes C15.0-C15.9 of the International Classification of Diseases (ICD) 10th revision and ICD-O-3 histology codes 8140-8575.

Statistical analysis. We calculated childhood BMI and height $z$-scores by age (per month). We used individuals with or without CPR numbers as an internal reference and the LMS method (Cole, $1990)$ to generate these $z$-scores. For BMI we used an age- and sexspecific reference from a period when the prevalence of obesity was low and stable (birth years 1955-1960). For height we used age-, sex- and birth cohort-specific references (5-year intervals). To obtain $z$-scores at the exact ages (that is, 7, 8, 9, 10, 11, 12 or 13 years) we used the $z$-score if measured at the exact age (that is, within the month of the individual's birthday); interpolated the $z$-score if the exact age measurement was not available but a measurement either side of the exact age ( \pm 12 months) were available; or extrapolated the $z$-score if the exact age measurement was not available and only a measurement one side of the exact age ( \pm 12 months) was available. In the absence of an exact age measurement and at least one measurement within 12 months of the exact age under scrutiny for an individual, a $z$-score was not generated and the individual was omitted from analyses for that particular age.

We tabulated the distribution of oesophageal adenocarcinoma cases, person-years and incidence rates per 100000 by age at diagnosis (5-year intervals) and birth cohort (10-year intervals). To assess relationships between childhood anthropometric variables and risk of oesophageal adenocarcinoma, we conducted Cox proportional hazards regression models using age as the underlying time metric with the baseline hazard stratified by birth cohort (5-year intervals) and sex. Follow-up began at the age of 40 years. The outcome was oesophageal adenocarcinoma while rightcensoring variables included date of death, emigration, loss to follow-up or 31 December 2011, whichever occurred first.

The proportional hazards assumption was tested for each age of anthropometric assessment by testing the effect of a time (age) varying $z$-score effect in the Cox proportional hazards regression models. We also assessed the shape of the associations between anthropometric $z$-scores and cancer risk using a categorical model and by visual inspection of restricted cubic spline plots (three knots) along with a Wald test against the linear alternative (that the linear model gives a sufficient modelling of the relationship compared with the restricted cubic spline). We also conducted models mutually adjusted for childhood BMI and childhood height in relation to oesophageal adenocraicnoma risk.

We tested whether sex and birth cohort (categorised 30-39, $40-49,50-59$ and $60-71$ years) were effect modifiers of the relationships between childhood anthropometric exposures and oesophageal adenocarcinoma risk, modelling the relationship linearly for each sex/birth cohort, estimating sex/birth cohortspecific hazard ratios (HRs) and comparing these HRs using a global test. Lastly, we also calculated population-attributable fractions (Ryan et al, 2010).

\section{RESULTS}

There were 255053 individuals (128330 males and 126723 females) included in our analytic cohort (Figure 1). During more than 5.4 million person-years of follow-up, there were 254 incident oesophageal adenocarcinoma cases (216 males and 38 females). Incidence rates increased with increasing age and with more recent birth cohorts (Table 1). For example, for the 1940-1949 birth cohort, rates progressively increased with age from 0.2 per 100000 person-years to $0.9,2.9,6.1,10.2,13.0$ and then 25.8. Across birth cohorts, rates progressively increased from 2.3 per 100000 personyears (1930-1939) to 11.8 (1960-69) for the age group 50-54 years. Body mass index was stable across birth cohorts, whereas height slightly increased with each subsequent birth cohort (data not shown).

Relationships between BMI $z$-score and oesophageal adenocarcinoma risk are shown in Table 2 and Figure 2. For males, HRs increased from 1.11 per BMI $z$-score at the age of 7 years, to 1.25 per BMI $z$-score at the age of 13 years and associations were statistically significant $(P<0.05)$ from ages 10 years onwards. Relationships for females similarly strengthened with age of BMI, peaking at 1.68 (95\% confidence interval (CI): 1.15, $2.45)$ per BMI $z$-score at the age of 13 years. These HRs were not significantly different between the sexes (Table 2). In an analysis 
Total population of boys and girls in the CSHRR

Born 1930 to 1989

$n=372636$

188360 males / 184276 females
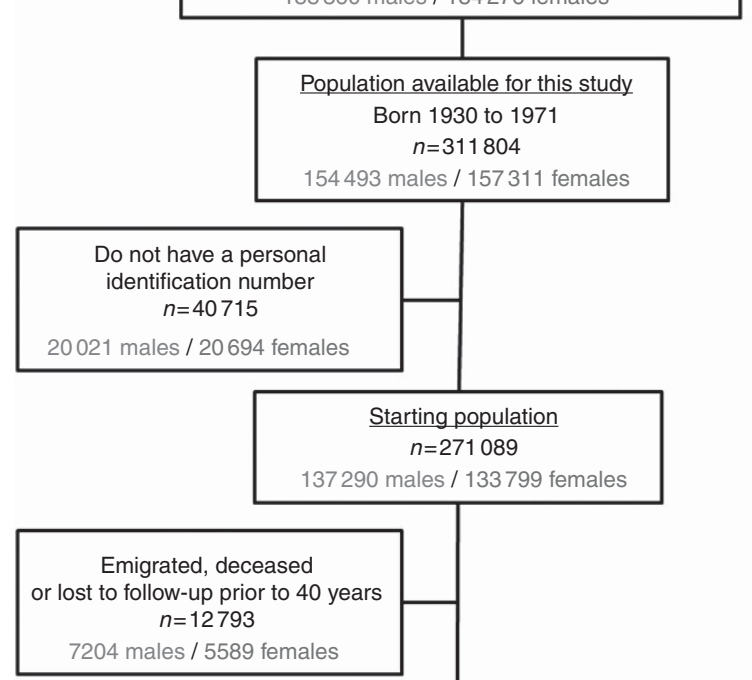

Eligible population, alive and living in Denmark at 40 years $n=258296$

130086 males / 128210 females

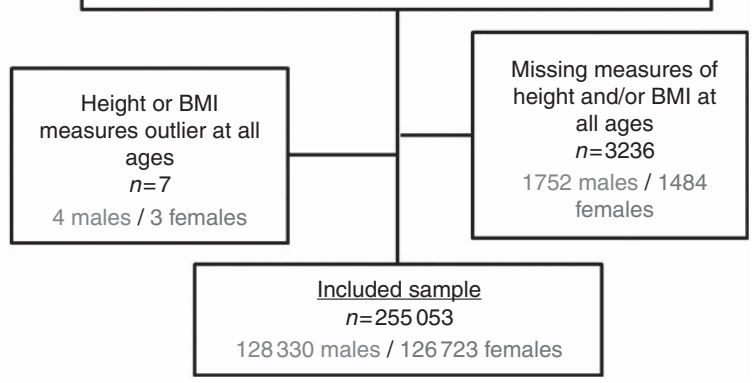

Figure 1. Flow chart of eligible and included subjects in the study.

that included both sexes, estimates of association were more similar to those from the male-only analysis, as may be expected, given the larger number of outcomes in this sex. There was little statistical support that these relationships with BMI differed by birth cohort or violated the proportional hazards assumption (data not shown). Restricted cubic spline models did tentatively suggest stronger cancer risk for children in the highest BMI centiles (Supplementary Figure and Supplementary Table 1), although statistical tests for departure from linearity were statistically significant only for ages of 9 years $(P=0.01)$ and 10 years $(P=0.02)$.

Table 3 shows the relationships between childhood height $z$-score and oesophageal adenocarcinoma risk. There was no evidence of a relationship in males $\left(\mathrm{HR}_{\mathrm{age}} 13\right.$ years $=1.04,95 \% \mathrm{CI}$ : $0.90,1.19)$. Conversely, in females the risk per unit increase in childhood height $z$-score was strong $\left(\mathrm{HR}_{\text {age }} 13\right.$ years $=1.77,95 \% \mathrm{CI}$ : $1.27,2.47)$ and stable across all ages at which height was measured. These HRs are statistically different $(P=0.004)$ showing an effect modification of height on risk of oesophageal adenocarcinoma by sex (Table 3). There were, however, very few cases among the females $(n=38)$. There was little evidence that these relationships with childhood height deviated from linearity or violated the proportional hazards assumption (data not shown). In an analysis of potential birth cohort effects, there was evidence that the relationship between childhood height $z$-score and oesophageal adenocarcinoma in females differed by birth cohort, although these stratified analyses were based on extremely small numbers of cases
(Supplementary Table 2). In models mutually adjusted for childhood BMI and childhood height, HRs for male BMI did not change, whereas HRs for male height underwent a very slight decrease (Supplementary Table 3). Female HRs decreased slightly more than male HRs in mutually adjusted models, but overall the effects of mutual adjustment were modest.

\section{DISCUSSION}

In this prospective analysis of measured childhood height and weight-which included 255053 individuals, 5.4 million person-years of follow-up, and 254 incident oesophageal adenocarcinoma cases-we find evidence for a linear and positive association between childhood BMI and future risk of oesophageal adenocarcinoma. In addition, increasing childhood height was associated with oesophageal adenocarcinoma in females but not in males.

To put our results in perspective, we calculated the populationattributable fractions for overweight and obesity at the age of 13 years of oesophageal adenocarcinoma as being $2.1 \%$ in boys and $7.2 \%$ in girls in our study. Population-attributable fractions become substantially higher if we extrapolate our associations to contemporary levels of overweight and obesityfor example, using combined US NHANES surveys (2007-2012) to estimate childhood overweight and obesity for the age of 13 years, with our estimates of effects at the age of 13 years, population-attributable fractions are $17.5 \%$ for boys and $36.9 \%$ for girls. This underscores the dramatic effect that the increased prevalence of childhood overweight and obesity may have on the future incidence of oesophageal adenocarcinoma, assuming a causal relationship.

Previous studies have consistently demonstrated a strong, doseresponse relationship between middle-aged BMI and oesophageal adenocarcinoma (Hoyo et al, 2012). The primary hypothesised mechanism underlying this relationship is disruption of the lower oesophageal sphincter, leading to gastroesophageal reflux disease (Friedenberg et al, 2008), Barrett's metaplasia (Chow et al, 1995; Lagergren et al, 1999a) and subsequent cancer. Alternatively, obesity may lead to oesophageal adenocarcinoma via the metabolic effect conferred by dysfunctional adipose tissue (Reid et al, 2010; Ryan et al, 2011).

Little other data are available for obesity at younger ages. Four case-control studies (Chow et al, 1998; Lagergren et al, 1999b; Cheng et al, 2000; Wu et al, 2001) and one prospective cohort (Merry et al, 2007) evaluated recalled weight, asking their middle-aged participants to recall their height and weight at different ages, including early adulthood. These studies suggest that having an overweight or obese BMI at age 18-and at later time points throughout adulthood-is associated with increased risk of oesophageal adenocarcinoma. However, each of these studies relied on participants remembering their weight from up to 50 years earlier, which is known to be inaccurate on the individual level (Tamakoshi et al, 2003; Dahl and Reynolds, 2013).

It is possible that children with higher BMI were at increased oesophageal adenocarcinoma risk due to their higher probability of adulthood obesity (Singh et al, 2008). Indeed, childhood BMI at the age of 7 years is moderately $(r \sim 0.5)$ and weakly $(r \sim 0.3)$ correlated with BMI at ages 25-35 years and 45 years, respectively (Singh et al, 2008; Macfarlane et al, 2011). On the other hand, childhood BMI has been positively associated with gastroesophageal reflux and its complications (Cooper et al, 1987; Tolaymat and Chapman, 1998; Malaty et al, 2009; Pashankar et al, 2009; Ruigomez et al, 2010; Koebnick et al, 2011; Nguyen et al, 2011) and gastroesophageal reflux is a noted risk factor for oesophageal 
Table 1. Number of cases and person-years, and crude incidence rate of oesophageal adenocarcinoma by age (5-year intervals) and birth cohort (10-year intervals)

\begin{tabular}{|c|c|c|c|c|c|c|}
\hline \multirow[b]{2}{*}{ Age (years) } & \multirow[b]{2}{*}{ Characteristics } & \multicolumn{5}{|c|}{ Birth cohort } \\
\hline & & 1930-1939 & 1940-1949 & 1950-1959 & 1960-1969 & 1970-1971 \\
\hline $40-44$ & $\begin{array}{l}\text { Cases (n) } \\
\text { P-Y of follow-up } \\
\text { IR per } 100000\end{array}$ & $\begin{array}{c}0 \\
321858\end{array}$ & $\begin{array}{c}1 \\
433799 \\
0.23\end{array}$ & $\begin{array}{c}4 \\
283934 \\
1.41\end{array}$ & $\begin{array}{c}2 \\
180036 \\
1.11\end{array}$ & $\begin{array}{c}0 \\
6063\end{array}$ \\
\hline $45-49$ & $\begin{array}{l}\text { Cases (n) } \\
\text { P-Y of follow-up } \\
\text { IR per } 100000\end{array}$ & $\begin{array}{c}2 \\
314894 \\
0.64\end{array}$ & $\begin{array}{c}4 \\
425150 \\
0.94\end{array}$ & $\begin{array}{c}6 \\
277837 \\
2.16\end{array}$ & $\begin{array}{c}2 \\
91144 \\
2.19\end{array}$ & $\begin{array}{l}0 \\
0\end{array}$ \\
\hline $50-54$ & $\begin{array}{l}\text { Cases (n) } \\
\text { P-Y of follow-up } \\
\text { IR per } 100000\end{array}$ & $\begin{array}{c}7 \\
304856 \\
2.30\end{array}$ & $\begin{array}{c}12 \\
412880 \\
2.91\end{array}$ & $\begin{array}{c}12 \\
249596 \\
4.81\end{array}$ & $\begin{array}{c}1 \\
8494 \\
11.77\end{array}$ & $\begin{array}{l}0 \\
0\end{array}$ \\
\hline $55-59$ & $\begin{array}{l}\text { Cases (n) } \\
\text { P-Y of follow-up } \\
\text { IR per } 100000\end{array}$ & $\begin{array}{c}15 \\
290747 \\
5.16\end{array}$ & $\begin{array}{c}24 \\
396153 \\
6.06\end{array}$ & $\begin{array}{c}11 \\
128652 \\
8.55\end{array}$ & $\begin{array}{l}0 \\
0\end{array}$ & $\begin{array}{l}0 \\
0\end{array}$ \\
\hline $60-64$ & $\begin{array}{l}\text { Cases }(n) \\
\text { P-Y of follow-up } \\
\text { IR per } 100000\end{array}$ & $\begin{array}{c}18 \\
271143 \\
6.64\end{array}$ & $\begin{array}{c}35 \\
344291 \\
10.17\end{array}$ & $\begin{array}{c}2 \\
12317 \\
16.24\end{array}$ & $\begin{array}{l}0 \\
0\end{array}$ & $\begin{array}{l}0 \\
0\end{array}$ \\
\hline $65-69$ & $\begin{array}{l}\text { Cases (n) } \\
\text { P-Y of follow-up } \\
\text { IR per } 100000\end{array}$ & $\begin{array}{c}29 \\
245660 \\
11.80\end{array}$ & $\begin{array}{c}20 \\
153890 \\
13.00\end{array}$ & $\begin{array}{l}0 \\
0\end{array}$ & $\begin{array}{l}0 \\
0\end{array}$ & $\begin{array}{l}0 \\
0\end{array}$ \\
\hline 70-74 & $\begin{array}{l}\text { Cases (n) } \\
\text { P-Y of follow-up } \\
\text { IR per } 100000\end{array}$ & $\begin{array}{c}30 \\
191847 \\
15.64\end{array}$ & $\begin{array}{c}3 \\
11636 \\
25.78\end{array}$ & $\begin{array}{l}0 \\
0\end{array}$ & $\begin{array}{l}0 \\
0\end{array}$ & $\begin{array}{l}0 \\
0\end{array}$ \\
\hline $75-79$ & $\begin{array}{l}\text { Cases (n) } \\
\text { P-Y of follow-up } \\
\text { IR per } 100000\end{array}$ & $\begin{array}{c}14 \\
66832 \\
20.95\end{array}$ & $\begin{array}{l}0 \\
0\end{array}$ & $\begin{array}{l}0 \\
0\end{array}$ & $\begin{array}{l}0 \\
0\end{array}$ & $\begin{array}{l}0 \\
0\end{array}$ \\
\hline $80-82$ & $\begin{array}{l}\text { Cases }(n) \\
\text { P-Y of follow-up } \\
\text { IR per } 100000\end{array}$ & $\begin{array}{c}0 \\
3869\end{array}$ & $\begin{array}{l}0 \\
0\end{array}$ & $\begin{array}{l}0 \\
0\end{array}$ & $\begin{array}{l}0 \\
0\end{array}$ & $\begin{array}{l}0 \\
0\end{array}$ \\
\hline
\end{tabular}

Table 2. Hazard ratios of the associations between per unit increase in childhood BMI z-score and oesophageal adenocarcinoma risk

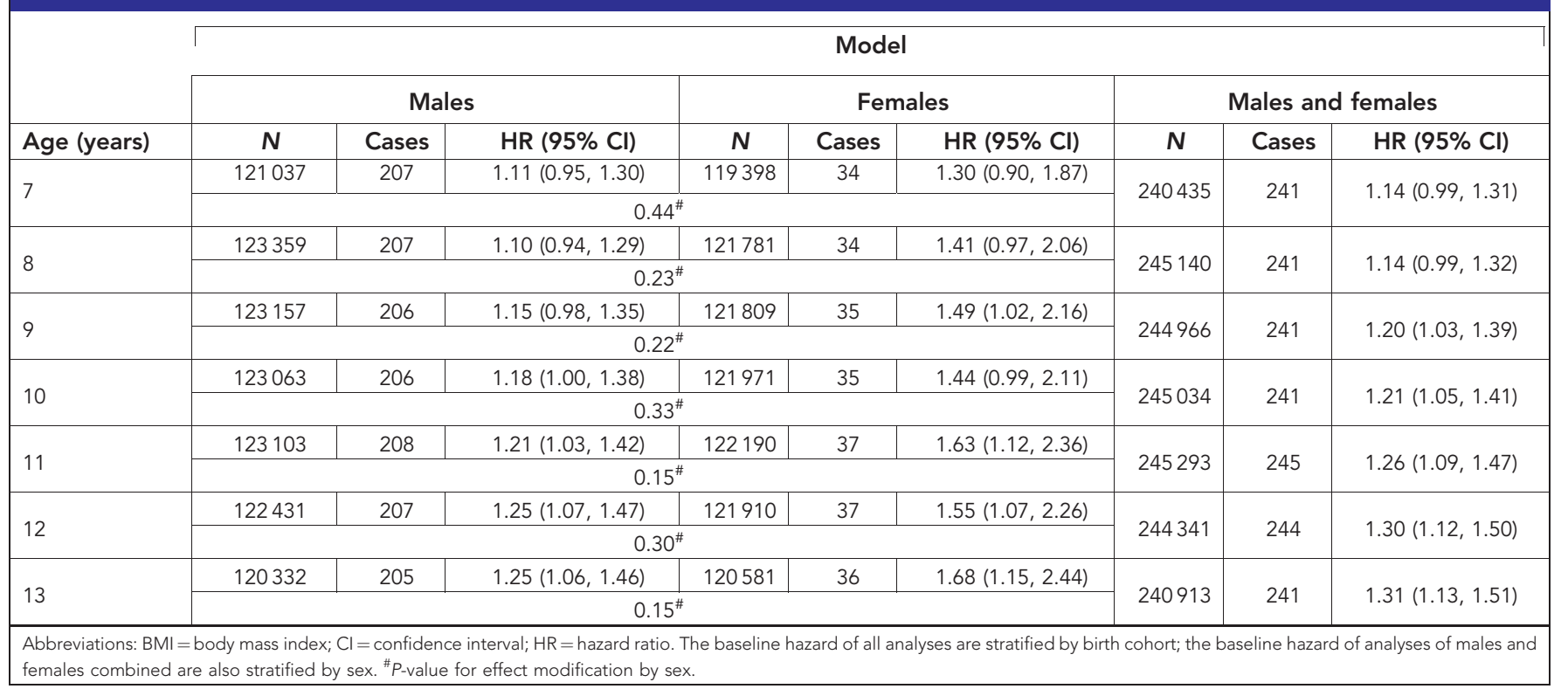

adenocarcinoma. Future studies with measured BMI across the lifespan are required to distinguish between these possibilities. In any case, the prevalence of childhood obesity has increased dramatically worldwide, such that a large proportion of contemporary birth cohorts will have been overweight or obese since childhood. These individuals are likely at particularly high risk of oesophageal adenocarcinoma and other obesity-associated diseases, underscoring the importance of effective childhood 
weight control programmes (Waters et al, 2011; Wang et al, 2013; Kelsey et al, 2014b). Moreover, there is growing evidence that longer duration (Abdullah et al, 2012; Pontiroli et al, 2013) and earlier age at onset of obesity (Boney, 2012; The et al, 2013) are associated with increased risks of disease, akin to the better understood temporal effects of cigarette smoking in relation to disease.

The positive association between childhood height and oesophageal adenocarcinoma risk in females, but not males in our study, should be interpreted with caution given the fact that there were only 38 oesophageal adenocarcinomas diagnosed in females. We are not aware of any prior study of childhood height in relation to oesophageal adenocarcinoma and the relationship with adult height is ambiguous with some reports finding no association (Engeland et al, 2004; Macinnis et al, 2006; Merry et al, 2007), others inverse (Chow et al, 1998; Lagergren

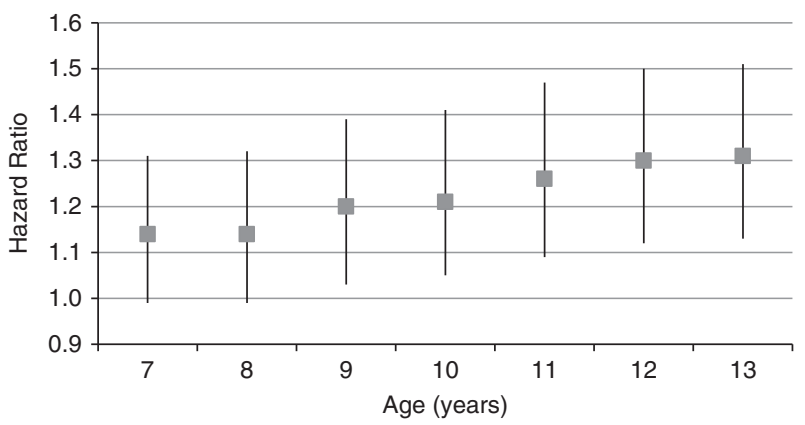

Figure 2. BMI in childhood and risk of oesophageal adenocarcinoma in adulthood. The graph depicts associations between childhood BMI and the risk of being diagnosed with oesopahgeal adenocarcinoma in adulthood. Hazard ratios and $95 \%$ confidence intervals are given for a 1 -unit increase in BMI $z$-score at each the age from 7 to 13 years. The data are from 255053 children (128330 boys) within the Copenhagen School Health Records Register. The associations were linear within each age, as determined from trend tests that rejected a nonlinear alternative. et al, 1999b) and one other positive (Wu et al, 2001). Although height at the age of 7-8 years is correlated with adult height ( $r=\sim 0.75$ ), factors related to childhood growth are considered to be partly distinct from those represented by eventual adult height (Li et al, 2007).

Strengths of this analysis include the following: a large cohort of individuals with serially measured heights and weights during childhood; database linkage via the ID number for highly accurate cancer outcome information through the Danish Cancer Registry (Gjerstorff, 2011) long follow-up and ability to examine possible birth cohort effects by stratification. Limitations of our analysis include the inability to adjust our estimates for social or lifestyle factors, either in childhood, or across the lifespan (Baker et al, 2009). However, there was little evidence for birth cohort influences on the childhood BMIoesophageal adenocarcinoma relationship despite dramatic changes in social conditions and lifestyle over the many birth cohorts (1930-1971) included in the study. Thus, it is less likely that these other factors have a role. Many biases are lessened, given the design of the study as well as the objective measures used for exposure assessment and outcome ascertainment. It has been suggested that GERD-independent mechanisms of oesophageal adenocarcinogenesis may result from altered metabolism of excess central (visceral) adiposity. Although we do not have measures of childhood central adiposity in this cohort to assess such, central adiposity is highly correlated with BMI even in children of similar ages to those included in this analysis (Pratesi, 2012). It was not an aim of this study to assess oesophageal squamous cell carcinoma, given the lack of an association with adult adiposity and the distinct pathogenesis relative to oesophageal adenocarcinoma. However, we have conducted a rudimentary analysis of this outcome and we can confirm that it is not associated with childhood BMI (Supplementary Table 4).

In conclusion, childhood BMI was associated with increased risk of oesophageal adenocarcinoma in adulthood. Whether childhood BMI is directly related to oesophageal adenocarcinoma, or associated indirectly through increased likelihood of adult obesity cannot be determined from our data. Nevertheless, our findings support lifestyle interventions targeted towards the growing number of overweight and obese children worldwide.

Table 3. Hazard ratios of the associations between per unit increase in childhood height z-score and oesophageal adenocarcinoma risk

\begin{tabular}{|c|c|c|c|c|c|c|c|c|c|}
\hline \multirow[b]{3}{*}{ Age (years) } & \multicolumn{9}{|c|}{ Model } \\
\hline & \multicolumn{3}{|c|}{ Males } & \multicolumn{3}{|c|}{ Females } & \multicolumn{3}{|c|}{ Males and females } \\
\hline & $N$ & Cases & $95 \% \mathrm{Cl}$ & $N$ & Cases & $95 \% \mathrm{Cl}$ & $N$ & Cases & $95 \% \mathrm{Cl}$ \\
\hline \multirow{2}{*}{7} & 121042 & 207 & $1.03(0.90,1.19)$ & 121042 & 34 & $1.74(1.24,2.45)$ & \multirow{2}{*}{240473} & \multirow{2}{*}{241} & \multirow{2}{*}{$1.11(0.98,1.26)$} \\
\hline & & & 0.0 & & & & & & \\
\hline \multirow{2}{*}{8} & 123364 & 207 & $1.02(0.89,1.17)$ & 123364 & 34 & $1.63(1.16,2.30)$ & \multirow{2}{*}{245151} & \multirow{2}{*}{241} & \multirow{2}{*}{$1.09(0.96,1.24)$} \\
\hline & & & 0.0 & & & & & & \\
\hline \multirow{2}{*}{9} & 123163 & 206 & $1.00(0.87,1.15)$ & 123163 & 35 & $1.73(1.23,2.42)$ & \multirow{2}{*}{244972} & \multirow{2}{*}{241} & \multirow{2}{*}{$1.08(0.95,1.23)$} \\
\hline & & & 0.0 & & & & & & \\
\hline \multirow{2}{*}{10} & 123066 & 206 & $1.02(0.89,1.17)$ & 123066 & 35 & $1.79(1.28,2.51)$ & \multirow{2}{*}{245040} & \multirow{2}{*}{241} & \multirow{2}{*}{$1.11(0.97,1.26)$} \\
\hline & & & 0.0 & & & & & & \\
\hline \multirow{2}{*}{11} & 123107 & 208 & $1.04(0.90,1.19)$ & 123107 & 37 & $1.79(1.30,2.48)$ & \multirow{2}{*}{245298} & \multirow{2}{*}{245} & \multirow{2}{*}{$1.13(0.99,1.28)$} \\
\hline & & & 0.0 & & & & & & \\
\hline \multirow{2}{*}{12} & 122433 & 207 & $1.03(0.90,1.19)$ & 122433 & 37 & $1.76(1.27,2.44)$ & \multirow{2}{*}{244344} & \multirow{2}{*}{244} & \multirow{2}{*}{$1.12(0.99,1.27)$} \\
\hline & & & 0.0 & & & & & & \\
\hline \multirow{2}{*}{13} & 120335 & 205 & $1.04(0.90,1.19)$ & 120335 & 36 & $1.77(1.27,2.47)$ & \multirow{2}{*}{240917} & \multirow{2}{*}{241} & \multirow{2}{*}{$1.12(0.99,1.28)$} \\
\hline & & & 0.0 & & & & & & \\
\hline
\end{tabular}




\section{ACKNOWLEDGEMENTS}

This study was funded by the Intramural Program of the National Cancer Institute, National Institutes of Health, Department of Health and Human Services and by the European Research Council-European Union's Seventh Framework Programme (FP/ 2007-2013)/ERC Grant Agreement no. 281418, childgrowth2cancer to JLB.

\section{CONFLICT OF INTEREST}

The authors declare no conflict of interest.

\section{REFERENCES}

Abdullah A, Wolfe R, Mannan H, Stoelwinder JU, Stevenson C, Peeters A (2012) Epidemiologic merit of obese-years, the combination of degree and duration of obesity. Am J Epidemiol 176: 99-107.

Abrams P, Levitt Katz LE (2011) Metabolic effects of obesity causing disease in childhood. Curr Opin Endocrinol Diabetes Obes 18: 23-27.

Adegboye AR, Andersen LB, Froberg K, Sardinha LB, Heitmann BL (2010) Linking definition of childhood and adolescent obesity to current health outcomes. Int J Pediatr Obes 5: 130-142.

Baker JL, Olsen LW, Andersen I, Pearson S, Hansen B, Sørensen TIA (2009) Cohort profile: the Copenhagen School Health Records Register. Int J Epidemiol 38: 656-662.

Baker JL, Olsen LW, Sorensen TI (2007) Childhood body-mass index and the risk of coronary heart disease in adulthood. $N$ Engl J Med 357: 2329-2337.

Boney CM (2012) Childhood onset and duration of obesity are significant risk factors for type 2 diabetes in mid-adulthood. Evid Based Nurs 15: 38-39.

Bua J, Olsen LW, Sørensen TIA (2007) Secular trends in childhood obesity in Denmark during 50 years in relation to economic growth. Obesity (Silver Spring) 15: 977-985.

Cheng KK, Sharp L, McKinney PA, Logan RF, Chilvers CE, Cook-Mozaffari P, Ahmed A, Day NE (2000) A case-control study of oesophageal adenocarcinoma in women: a preventable disease. Br J Cancer 83: $127-132$.

Chow WH, Blot WJ, Vaughan TL, Risch HA, Gammon MD, Stanford JL, Dubrow R, Schoenberg JB, Mayne ST, Farrow DC, Ahsan H, West AB, Rotterdam H, Niwa S, Fraumeni Jr. JF (1998) Body mass index and risk of adenocarcinomas of the esophagus and gastric cardia. J Natl Cancer Inst 90: $150-155$.

Chow WH, Finkle WD, McLaughlin JK, Frankl H, Ziel HK, Fraumeni Jr. JF (1995) The relation of gastroesophageal reflux disease and its treatment to adenocarcinomas of the esophagus and gastric cardia. JAMA 274: 474-477.

Claire Wang Y, Gortmaker SL, Taveras EM (2011) Trends and racial/ethnic disparities in severe obesity among US children and adolescents, 1976-2006. Int J Pediatr Obes 6: 12-20.

Cole TJ (1990) The LMS method for constructing normalized growth standards. Eur J Clin Nutr 44: 45-60.

Cook MB, Chow WH, Devesa SS (2009) Oesophageal cancer incidence in the United States by race, sex, and histologic type, 1977-2005. Br J Cancer 101: 855-859.

Cooper JE, Spitz L, Wilkins BM (1987) Barrett's esophagus in children: a histologic and histochemical study of 11 cases. J Pediatr Surg 22: 191-196.

Dahl AK, Reynolds CA (2013) Accuracy of recalled body weight-a study with 20-years of follow-up. Obesity (Silver Spring) 21: 1293-1298.

Derakhshan MH, Robertson EV, Fletcher J, Jones G-R, Lee YY, Wirz AA, McColl KEL (2011) Mechanism of association between BMI and dysfunction of the gastro-oesophageal barrier in patients with normal endoscopy. Gut 61(3): 337-343.

Engeland A, Tretli S, Bjorge T (2004) Height and body mass index in relation to esophageal cancer; 23-year follow-up of two million Norwegian men and women. Cancer Causes Control 15: 837-843.
Friedenberg FK, Xanthopoulos M, Foster GD, Richter JE (2008)

The association between gastroesophageal reflux disease and obesity. Am J Gastroenterol 103: 2111-2122.

Hoyo C, Cook MB, Kamangar F, Freedman ND, Whiteman DC, Bernstein L, Brown LM, Risch HA, Ye W, Sharp L, Wu AH, Ward MH, Casson AG, Murray LJ, Corley DA, Nyren O, Pandeya N, Vaughan TL, Chow WH, Gammon MD (2012) Body mass index in relation to oesophageal and oesophagogastric junction adenocarcinomas: a pooled analysis from the International BEACON Consortium. Int J Epidemiol 41: 1706-1718.

Kelsey MM, Zaepfel A, Bjornstad P, Nadeau KJ (2014a) Age-related consequences of childhood obesity. Gerontology 60(3): 222-228.

Kelsey MM, Zaepfel A, Bjornstad P, Nadeau KJ (2014b) Age-related consequences of childhood obesity. Gerontology 60: 222-228.

Koebnick C, Getahun D, Smith N, Porter AH, Der-Sarkissian JK, Jacobsen SJ (2011) Extreme childhood obesity is associated with increased risk for gastroesophageal reflux disease in a large population-based study. Int J Pediatr Obes 6: e257-e263.

Kong CY, Nattinger KJ, Hayeck TJ, Omer ZB, Wang YC, Spechler SJ, McMahon PM, Gazelle GS, Hur C (2011) The impact of obesity on the rise in esophageal adenocarcinoma incidence: estimates from a disease simulation model. Cancer Epidemiol Biomarkers Prev.

Kroep S, Lansdorp-Vogelaar I, Rubenstein JH, Lemmens V. E. P. P., van Heijningen EB, Aragones N, van Ballegooijen M, Inadomi JM (2014) Comparing trends in esophageal adenocarcinoma incidence and lifestyle factors between the United States, Spain, and The Netherlands. Am J Gastroenterol 109: 336-343.

Kubo A, Cook MB, Shaheen NJ, Vaughan TL, Whiteman DC, Murray L, Corley DA (2013) Sex-specific associations between body mass index, waist circumference and the risk of Barrett's oesophagus: a pooled analysis from the international BEACON consortium. Gut 62(12): 1684-1691.

Lagergren J, Bergstrom R, Lindgren A, Nyren O (1999a) Symptomatic gastroesophageal reflux as a risk factor for esophageal adenocarcinoma. $N$ Engl J Med 340: 825-831.

Lagergren J, Bergstrom R, Nyren O (1999b) Association between body mass and adenocarcinoma of the esophagus and gastric cardia. Ann Int Med 130: $883-890$

Li L, Dangour AD, Power C (2007) Early life influences on adult leg and trunk length in the 1958 British birth cohort. Am J Hum Biol 19: 836-843.

Lofdahl HE, Lane A, Lu Y, Lagergren P, Harvey RF, Blazeby JM, Lagergren J (2011) Increased population prevalence of reflux and obesity in the United Kingdom compared with Sweden: a potential explanation for the difference in incidence of esophageal adenocarcinoma. Eur J Gastroenterol Hepatol 23: 128-132.

Macfarlane GJ, de Silva V, Jones GT (2011) The relationship between body mass index across the life course and knee pain in adulthood: results from the 1958 birth cohort study. Rheumatology (Oxford) 50: 2251-2256.

Macinnis RJ, English DR, Hopper JL, Giles GG (2006) Body size and composition and the risk of gastric and oesophageal adenocarcinoma. Int J Cancer 118: 2628-2631.

Malaty HM, Fraley JK, Abudayyeh S, Fairly KW, Javed US, Aboul-Fotouh H, Mattek N, Gilger MA (2009) Obesity and gastroesophageal reflux disease and gastroesophageal reflux symptoms in children. Clin Exp Gastroenterol 2: $31-36$.

Merry AH, Schouten LJ, Goldbohm RA, van den Brandt PA (2007) Body mass index, height and risk of adenocarcinoma of the oesophagus and gastric cardia: a prospective cohort study. Gut 56(11): 1503-1511.

Nguyen DM, El-Serag HB, Shub M, Integlia M, Henderson L, Richardson P, Fairly K, Gager MA (2011) Barrett's esophagus in children and adolescents without neurodevelopmental or tracheoesophageal abnormalities: a prospective study. Gastrointest Endosc 73: 875-880.

Pandolfino JE, El-Serag HB, Zhang Q, Shah N, Ghosh SK, Kahrilas PJ (2006) Obesity: a challenge to esophagogastric junction integrity. Gastroenterology 130: 639-649.

Pashankar DS, Corbin Z, Shah SK, Caprio S (2009) Increased prevalence of gastroesophageal reflux symptoms in obese children evaluated in an academic medical center. J Clin Gastroenterol 43: 410-413.

Pontiroli AE, Alberto M, Paganelli M, Saibene A, Busetto L (2013) Metabolic syndrome, hypertension, and diabetes mellitus after gastric banding: the role of aging and of duration of obesity. Surg Obes Relat Dis 9: 894-900.

Reid BJ, Li X, Galipeau PC, Vaughan TL (2010) Barrett's oesophagus and oesophageal adenocarcinoma: time for a new synthesis. Nat Rev Cancer 10: $87-101$. 
Ruigomez A, Lundborg P, Johansson S, Wallander MA, Garcia Rodriguez LA (2010) Follow-up of a cohort of children and adolescents with gastroesophageal reflux disease who were free of reflux esophagitis at initial diagnosis. Scand J Gastroenterol 45: 814-821.

Ryan AM, Duong M, Healy L, Ryan SA, Parekh N, Reynolds JV, Power DG (2011) Obesity, metabolic syndrome and esophageal adenocarcinoma: epidemiology, etiology and new targets. Cancer Epidemiol 35: 309-319.

Ryan BM, Robles AI, Harris CC (2010) Genetic variation in microRNA networks: the implications for cancer research. Nat Rev Cancer 10: 389-402.

Singh AS, Mulder C, Twisk JWR, van Mechelen W, Chinapaw MJM (2008) Tracking of childhood overweight into adulthood: a systematic review of the literature. Obes Rev 9: 474-488.

Tamakoshi K, Yatsuya H, Kondo T, Hirano T, Hori Y, Yoshida T, Toyoshima H (2003) The accuracy of long-term recall of past body weight in Japanese adult men. Int J Obes Relat Metab Disord 27: 247-252.

The NS, Richardson AS, Gordon-Larsen P (2013) Timing and duration of obesity in relation to diabetes: findings from an ethnically diverse, nationally representative sample. Diabetes Care 36: 865-872.
Tolaymat N, Chapman DM (1998) Gastroesophageal reflux disease in children older than two years of age. WV Med J 94: 22-25.

Wang Y, Wu Y, Wilson RF, Bleich S, Cheskin L, Weston C, Showell N, Fawole O, Lau B, Segal J (2013) Childhood Obesity Prevention Programs: Comparative Effectiveness Review and Meta-Analysis Rockville, MD.

Waters E, de Silva-Sanigorski A, Hall BJ, Brown T, Campbell KJ, Gao Y, Armstrong R, Prosser L, Summerbell CD (2011) Interventions for preventing obesity in children. Cochrane Database Syst Rev CD001871.

Wu AH, Wan P, Bernstein L (2001) A multiethnic population-based study of smoking, alcohol and body size and risk of adenocarcinomas of the stomach and esophagus (United States). Cancer Causes Control 12: $721-732$.

This work is published under the standard license to publish agreement. After 12 months the work will become freely available and the license terms will switch to a Creative Commons AttributionNonCommercial-Share Alike 4.0 Unported License.

Supplementary Information accompanies this paper on British Journal of Cancer website (http://www.nature.com/bjc) 